\title{
Evaluation of proliferation and survival of spleen immune cells treated by Deacetylchitin nanoparticles on breast cancer mouse model
}

\author{
Neda Soleimani'*, Ashraf Mohabati mobarez', Nima Khoramabadi ${ }^{r}$
}

Received: 16 Feb, 2017; Accepted: 19 Apr, 2017

\begin{abstract}
Background \& Aims: Breast cancer is the most common carcinoma in women and one of the main causes of death in developed and developing countries. Today, compounds with immunolodulator properties can be replaced with routine drugs. One of them is Deacetylchitin. This study aimed to evaluate proliferation and survival of spleen immune cells treated by Deacetylchitin nanoparticles on breast cancer mouse model.

Materials \& Methods: Deacetylchitin nanoparticles were prepared by ionic gelation method. Zeta Sizer device measured electrical charge of nanoparticles and their size was measured by DLS and SEM. The tumor was created within two weeks after injection to $\mathrm{BALB} / \mathrm{c}$ mice and then different mice groups were treated with Deacetylchitin nanoparticles and controls with PBS. After three weeks, the mice were sacrificed. The proliferation and survival of spleen lymphocyte was evaluated by MTT.

Results: Deacetylchitin nanoparticles induce proliferation of spleen cells culture. Lymphocyte proliferation showed a significant increase in Deacetylchitin nanoparticles of treated group compared to control $(\mathrm{p}<0.05)$.

Conclusion: Our findings suggest that chitosan nanoparticles can stimulate the immune system and proliferate lymphocytes. This combination can be used as a medicinal supplement to stimulate the immune system to be effective in immunotherapy.
\end{abstract}

Keywords: Immunotherapy, Deacetylchitin, Breast cancer

Address: Tehran, Department of Microbiology and Microbial Biotechnology, Faculty of Life Sciences and Biotechnology, Shahid Beheshti University

Tel: (+98) 2129905516

Email: N_soleimani@sbu.ac.ir

\section{Introduction}

Breast cancer is the most common malignant disease in women and one of the main causes of death in developed and developing countries. Although Iran is one of the countries with low incidence of breast cancer than others, the increase in its incidence in recent years has determined the disease as the most common malignancy among women (1). Current treatments of cancer possibly reduce tumor size, but are transient and have no positive impact on patient survival, with a risk of recurrence of the disease (2). Therefore, the need for replacement with more effective and a specific therapy with fewer side effects are required. High prevalence of breast cancer at early ages in Iran and complications of

\footnotetext{
${ }^{1}$ Department of Microbiology and Microbial Biotechnology, Faculty of Life Sciences and Biotechnology, Shahid Beheshti University, Tehran, Iran (Corresponding Author)

${ }^{2}$ Department of bacteriology, Tarbiat modares University, Tehran, Iran

${ }^{3}$ PhD. of Medical Bacteriology, Department of bacteriology, Tarbiat modares University, Tehran, Iran
} 
the disease for families raise the necessity of the research for the introduction of new therapeutic substances with immunomodulatory properties and fewer side effects (3-5).

Today, compounds with immunolodulator properties can be replaced with routine drugs. Deacetylchitin is one of them. Chitin and its derivatives such as chitosan - carboxymethyl chitin, and dihydroxypropyl chitin have immune modulatory effects and increase cell activity, secretion of cytokines and chemokines by affecting on the innate and adaptive immune system. Since chitin and its derivatives do not exist in the structure of the human body, its presence is an activator of the immune system and some receptors such as Detectin-1, TLR-2 and mannose are responsible for identifying it on the surface of immune cells. Suspension and Deacetylchitin particles have the ability to stimulate the immune system as chemotaxis and activation of macrophages (6-11).

Given the importance of the immune system, especially cellular immune responses in anti-tumor defense and its overcome to humoral immunity as an important factor in anti-tumor defense, the activity can cause the death of cancer cells if Deacetylchitin nanoparticles lead the activation of the immune system and spleen cell proliferation. Therefore, the combination with other anticancer drugs will be discussed as a combination of immune booster and immunolodulator. The aim of this study was to evaluate the stimulation of immune cells and third proliferation in the interaction with Deacetylchitin nanoparticles.

\section{Materials and Methods}

This study is interventional. $1 \mathrm{mg}$ per $\mathrm{ml}$ of Deacetylchitin was dissolved initially in 1\% acetic acid solution for production and preparation of nanoparticles. Deacetylchitin solution was put on the stirrer with a speed of 400 at room temperature. Tripolyphosphate (TPP) $0.1 \%$ was prepared in distilled water and TPP solution was added once to Deacetylchitin using ion gel method. The reaction continued for 1 hour under these conditions. Electron microscope was used to study the characteristics of bonded particles, their shape, size, dispersion and uniformity and ZETA SIZER (Malvern) was used to determine the electrical charge. Nanoparticles had been isolated from free Deacetylchitin parts using centrifuges at a speed of $18,000 \mathrm{rpm}$ for 30 minutes at $15^{\circ} \mathrm{C}(14,15)$. To evaluate the effects of nanoparticles, thirty 5 to 6-week old female BALB / c rats were obtained from Pasteur Institute of Iran. Tumor cells of line 4T1 were used to establish tumor model. The mice were divided into three groups. The first group was tumor mice treated with nanoparticles Deacetylchitin. The second group received normal saline and the third group was healthy mice without tumors. The rate of tumor growth was measured on a daily basis and recorded. To assess survival time, a group of mice were studied with a period of 45 to 60-day treatment. 18 days after injection of nanoparticles Deacetylchitin and physiological saline, the rats were sacrificed and their spleen cells were extracted for isolation and culture of spleen cells.

Spleen cell suspension was prepared on the basis of 0.5 $\times 10^{6}$ cells per $\mathrm{ml}$ and were cultured in the 24 -hole plates in the presence of enriched RPMI medium (27). Then, the mouse spleen cells were tested with case group and the lysate of cancer cells were stimulated and incubated in an incubator containing 5\% carbon dioxide for 48 hours at $37^{\circ} \mathrm{C}$. Cell proliferation rate test was performed by MTT on spleen cells $(16,17)$.

MTT test is based on reduction of MTT [3- (4, 5Dimethylthiazol-2-yl) -2,5- Diphenyltetrazolium Bromide] which represents the intracellular metabolic activity; The more the number of cells are, the higher the MTT reduction will be and vice versa (12). 20 micro liters (5mg/ml PBS) MTT (company Merk England) was added to the wells after 48 hours of spleen cells culture and incubated for 4 hours at $37^{\circ} \mathrm{C}$. After 
incubation, the supernatant was removed slowly and 100 micro liters of DMSO (Sigma-Aldrich Company of America) was added to the wells to dissolve formed frmazan crystals and create the color. The absorption of the wells was read at $570 \mathrm{~nm}$. The results were calculated in terms of stimulation index (Stimulation Index: SI) and the SI is negative for absorption 570 per test to 570 of controls (18).

\section{Statistical analysis:}

This study is interventional. Data was reported as mean $\pm \mathrm{SD}$ and statistical analysis of test data was performed using variance (ANOVA) followed by Tukey test.
Results were reviewed using SPSS and Prism6 and $\mathrm{P} \leq 0.001$ was interpreted as significant.

\section{Results}

Particle size, distribution and uniformity of Deacetylchitin have been determined by DLS (Malvern). Figure 1 shows Deacetylchitin particles size at $\mathrm{pH} 6$ and the average size of the nanoparticles was $210 \mathrm{~nm}$ after three replications. DLS device data on the sample revealed that the size range of more than 95 percent of the tested samples were $210 \mathrm{~nm}$ with higher peak and about 5 percent of the others were in the range of 20 to $70 \mathrm{~nm}$ with an average of $45 \mathrm{~nm}$.

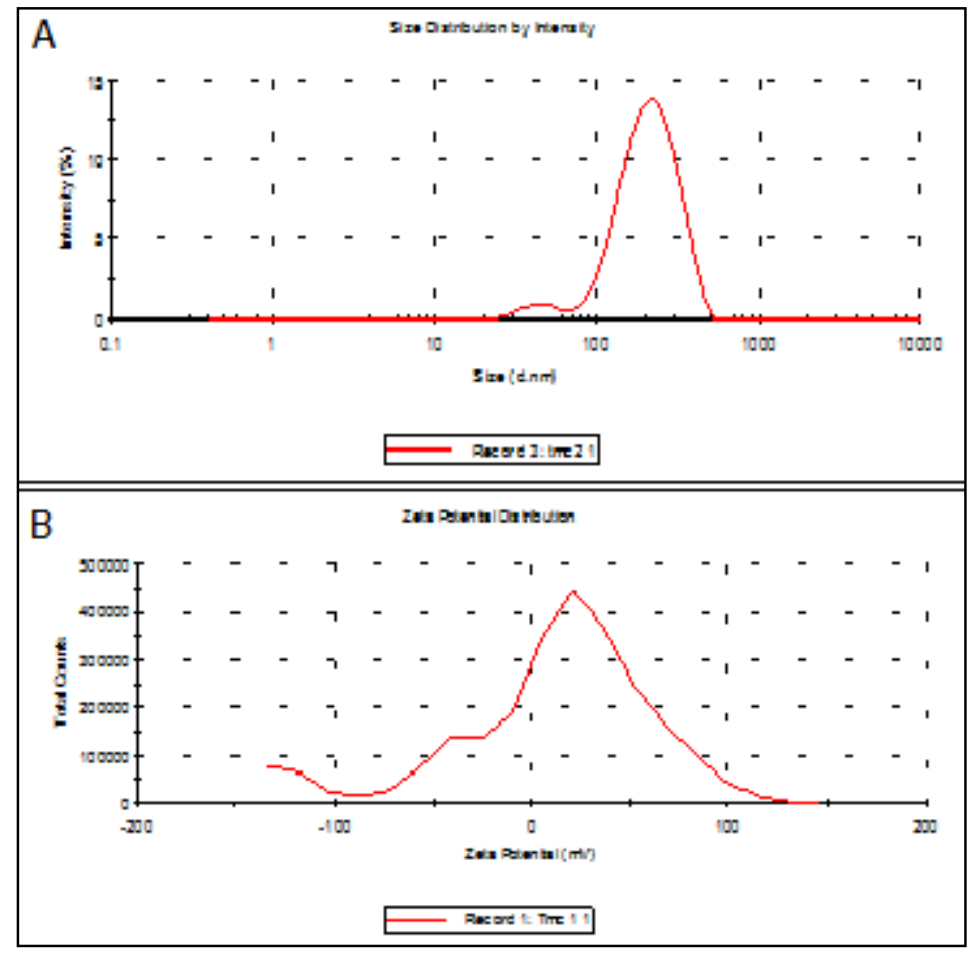

\section{Figure 1:}

A. Particle Size of Deacetylchitin with DLS based on nanometer.

B. Electric charge of Deacetylchitin with ZETA SIZER based on millivolts

Electric charge, dispersion and uniformity of Deacetylchitin nanoparticles have been determined by ZETA SIZER (Malvern). Figure 2 shows Deacetylchitin nanoparticles electric charge at $\mathrm{pH}$ 6. An average electric charge of Deacetylchitin with three replications was determined as $11+\mathrm{mV}$. DLS device data showed that the graph was single peak with homology. The electron beam interaction with the matter particles showed the appearance of nanoparticles. Beams emitted from these interactions can be used to survey. Figure 2 shows Deacetylchitin nanoparticles images in SEM microscope. 


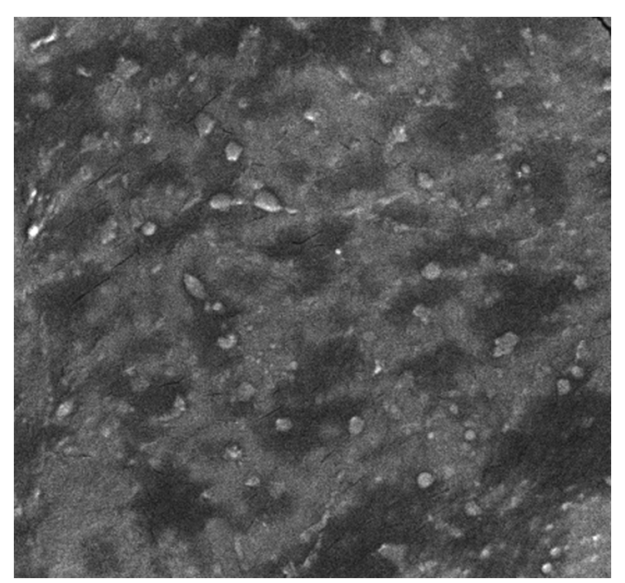

Figure 2: Deacetylchitin nanoparticles images in SEM microscope

The tumor size was measured in the studied groups with a digital caliper. The results of treatment with nanoparticles Deacetylchitin showed that the tumor size was reduced compared with the untreated group. This reduction in size was statistically significant compared with the control group. MTT test was used to evaluate the effects of Deacetylchitin nanoparticles in a tumor model on the proliferation of immune cells of spleen. The results are calculated in terms of stimulation index (Stimulation Index: SI) and SI of absorption rate is 570 per test to 570 untreated controls. Based on the results shown in Figure 3, the rate of growth and proliferation of immune cells in spleen in rats treated with nanoparticles within 24 hours showed a significant 2times increase compared with the control group. However, tumor untreated groups and less healthy rats showed less growth compared with the control group and this difference was statistically significant $(\mathrm{P}>$ 0.05). Figure 1 clearly shows an increased Deacetylchitin nanoparticles stimulatory effect on these cells.

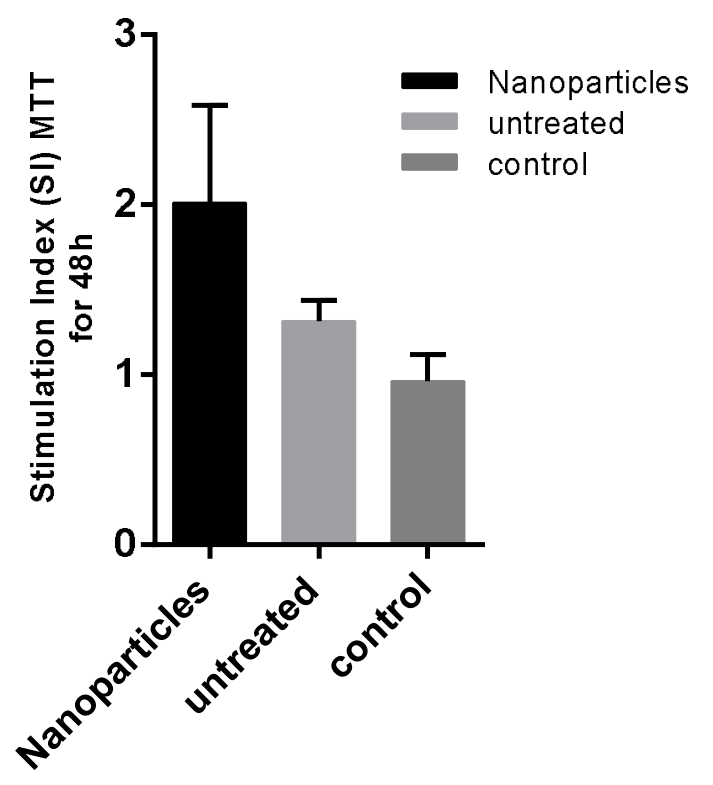


Figure 3: The proliferation of mouse spleen cells as a result of treatment with Deacetylchitin nanoparticles compared with the control group.
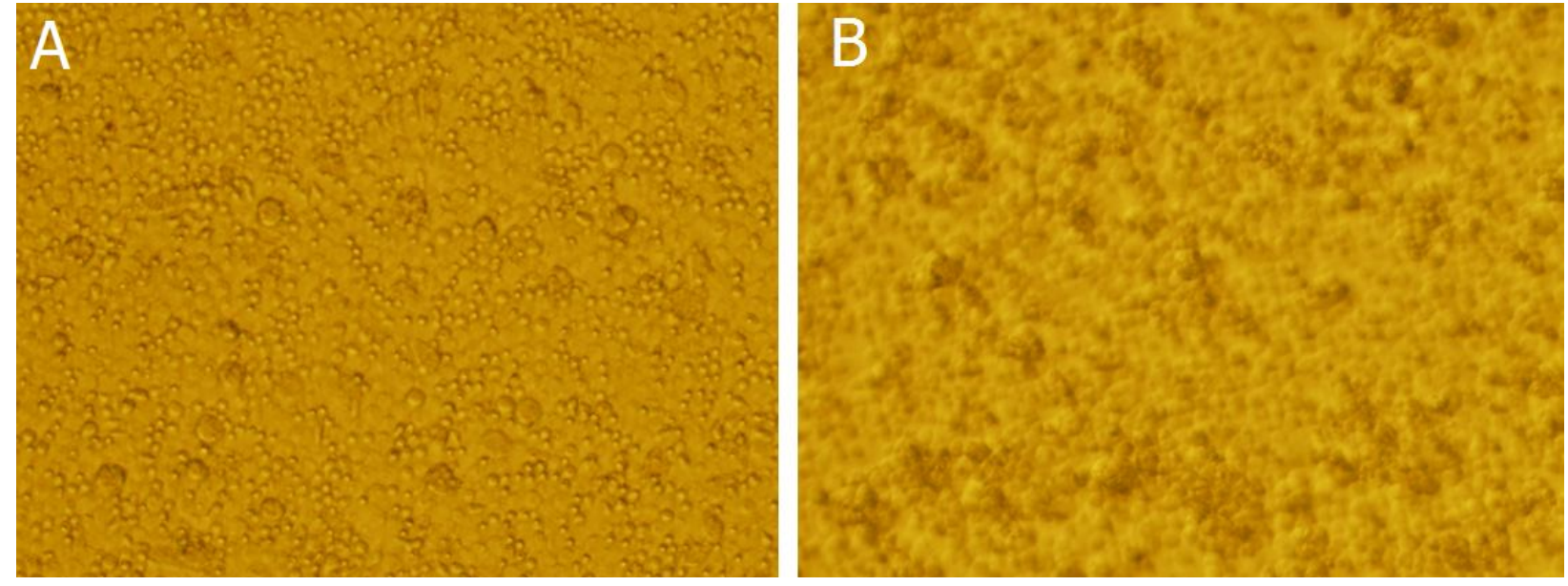

Figure 3. A. Not stimulated spleen cells of controls B. Stimulated and amplified spleen cells of test group

\section{Discussion}

Information obtained from the physical and chemical properties of Deacetylchitin lead the propose of the polymer as a material for drug delivery and release, especially for macromolecules. Technically, the characteristics of dissolvent in water and positive charges of Deacetylchitin are very important (12). The characteristics make the polymer to have interaction with macro molecules with the negative charges in an aqueous environment or charged surfaces cells. The use of polymers such as Deacetylchitin is of great interest in delivery of drugs to the appropriate place in biological systems. Given the applications of Deacetylchitin, Zhang used nanoparticles Deacetylchitin in his study as drug carriers (20). Vila et al. used Deacetylchitin nanoparticles as protein carrier in tetanus vaccine (19). Hossein Zadeh and colleagues have used Deacetylchitin nanoparticles as a drug delivery system in cancer treatment (15).

In 2016, Potdar et al showed that chitosan nanoparticles can inhibit the occurrence of metastasis in esophageal cancer cells (21). In a survey in 2013, Solomon and colleagues showed that the inhibitory effects of drug against cancer cells is higher in combination with chitosan nanoparticles compared to when the drug is used alone (22). In 2014, results of Wimardhani et al. showed that chitosan produced apoptosis-inducing and anticancer effects in digestive tract cancer cells (23). Studying chitosan Rauw et al. (2010) concluded that the combination can lead to activation of immune cells and induces responses of lymphocytes type Th1 (24). In this study, we scrutinized the body's immune cells' response to the effects of Deacetylchitin nanoparticles in vivo as a treatment option. The size range of 100 to 250 nanometers of nanoparticles has the ability to stimulate the immune system (25).

An average Deacetylchitin particle size was determined as about $200 \mathrm{~nm}$ with DLS. The size was verified by SEM device that is indicative of fit within this range. Deacetylchitin nanoparticles, as chemotaxis, are capable of stimulating the immune system, activating macrophages and increase phagocytosis activity (26). This size of nanoparticles stimulated spleen cells as well. Tumor size in the treated groups decreased with Deacetylchitin particles. This reduction in size showed a significant difference compared with the control group. This reduction in tumor size reflects 
that the composition can well activate the immune system by stimulating it and the appropriate responses will reduce tumor size. Stimulation of spleen cells and lymphocyte proliferation cause secretion of multiple cytokines and stimulate the immune system. Activation of cells is important at the beginning of the formation of the responses. If a combination lead to the proliferation of lymphocyte clones, an appropriate response will be shaped based on the type of antigen. In this regard, Deacetylchitin nanoparticles could well stimulate lymphocyte clones. Stimulation of the immune system and cell proliferation cause the immune system to activate which causes cells not to be neutral against cancer cell and exhibits an appropriate response. The type of activation path is important. Since reduction in tumor size was observed followed by the activation of

\section{References}

1. Hashemzadeh S, Aligholipour Maleki R, Golzari SE. The incidence of breast cancer in northwest iran (2003 -2008). J Cardiovasc Thorac Res 2012;4(1):5-9.

2. Duffy M. CA 15-3 and related mucins as circulating markers in breast cancer. Ann Clin Biochem 1999; 5: 579-86.

3. Man Y, Stojadinovic A, Mason J. Tumor-Infiltrating Immune Cells Promoting Tumor Invasion and Metastasis: Existing Theories. J Cancer 2013; 4(1): 84-95.

4. Kahlenborn C, Modugno F, Potter DM, Severs WB. Oral contraceptive use as a risk factor for premenopausal breast cancer: a meta-analysis. Mayo Clin Proc 2006; 81(10): 1290-302.

5. Nelson HD, Zakher B, Cantor A, Fu R, Griffin J, O'Meara ES, et al. Risk factors for breast cancer for women aged 40 to 49 years: a systematic review and meta-analysis. Ann Intern Med 2012; 156(9): 635-48.

6. Russo J, Rivera R, Russo IH. Influence of age and parity on the development of the human breast. Breast Cancer Res Treat 1992; 23(3): 211-8. the system and the proliferation of clones, it can be understood that the reduction can be achieved by activating the pathway Th1 and cell safety which reduces the size of the tumor cell. The exact molecular mechanism of reduction in tumor size is discussed in the case group which was direct and through the cytotoxic effect of nanoparticles, or indirect through inhibition of the immune system leading reduction in size requiring further studies.

Due to the unique features, Deacetylchitin nanoparticles will not only be discussed to deliver a variety of drugs and anticancer drugs, but also as a treatment option along with supplements. Therefore, future studies are necessary to assess the impact of Deacetylchitin on the various signaling pathways and anti-tumor activity.

7. Townsend CM, Jr. Treatment of breast cancer. Clin Symp 1997; 49(1):1-32.

8. Ueda T, Volinia S, Okumura H, Shimizu M, Taccioli C, Rossi S, et al. Relation between microRNA expression and progression and prognosis of gastric cancer: a microRNA expression analysis. Lancet Oncol 2010;11:136-46.

9. Stockler M, Wilcken NR, Ghersi D, Simes RJ. Systematic reviews of chemotherapy and endocrine therapy in metastatic breast cancer. Cancer Treat Rev 2000;26(3):151-68.

10. Sieval A, Thanou M, Kotze A.F, Verhoef C.J, Brussee J, Junginger H.E. Preparation and NMR characterization of highly substituted N-trimethyl chitosan chloride. Carbohydrt Polym 1998; 36, 157-65.

11. Grinberg O, Gedanken A, Patra CR, Patra S, Mukherjee P, Mukhopadhyay D. Sonochemically prepared BSA microspheres containing Gemcitabine, and their potential application in renal cancer therapeutics. Acta Biomater 2009;5(8):3031-7. 
12. Tan ML, Choong PF, Dass CR. Review: doxorubicin delivery systems based on chitosan for cancer therapy. J Pharm Pharmacol 2009; 61(2): 131-42.

13. Saremi Sh, Atyabi F, Parinaz Akhlaghi S, Nasser Ostad S, Dinarvand R. Thiolated chitosan nanoparticles for enhancing oral absorption of docetaxel: preparation, in vitro and ex vivo evaluation. Int J Nanomedicine 2011; 6: 119-28.

14. Soleimani N, Mobarez A, Jafari Olia M, Atyabi F. Synthesis, Characterization and Effect of the Antibacterial Activity of Chitosan Nanoparticles on Vancomycin- Resistant Enterococcus and Other Gram Negative or Gram Positive Bacteria. Int J Pure Appl Sci Tech 2015: 26(1): 14-23.

15. Hosseinzadeh H, Atyabi F, Dinarvand R, Naser Ostad S. Chitosan-Pluronic nanoparticles as oral delivery of anticancer gemcitabine: preparation and in vitro study. Int J Nanomedicine 2012; 7: 1851-63.

16. Soleimani N, Mohabati-Mobarez A, Atyabi F, HasanSaraf Z, Haghighi M. Preparation of chitosan nanoparticles carrying recombinant helicobacter pylori neutrophil-activating protein. J Mazandaran Univ Med Sci 2014; 23 (2) 23 (2):134-44.

17. Daneshmandi S, Hajimoradi M, Soleimani N, Sattari M. Modulatory effect of Acetobacter xylinum cellulose on peritoneal macrophages. Immunopharmacol Immunotoxicol2011: 33 (1), 164-8.

18. Yousofi A, Daneshmandi S, Soleimani N, Bagheri K, Karimi MH. Immunomodulatory effect of Parsley (Petroselinum crispum) essential oil on immune cells: mitogen-activated splenocytes and peritoneal macrophages. Immunopharmacol Immunotoxicol 2012: 34 (2), 303-8.

19. Vila A and et al. Low molecular weight chitosan nanoparticles as new carriers for nasal vaccine delivery in mice. Eur J Pharm Biopharm 2004; 57: 123-31.

20. Zhang H, Wu S, Tao Y, Zang L, Su Z. Preparation and characterization of water-soluble chitosan nanoparticles as protein delivery system. J Nanomaterials 2010;5:1-5.

21. Potdar PD, Shetti AU. Evaluation of antimetastatic effect of chitosan nanoparticles on esophageal cancer associated fibroblasts. J Cancer Metasta Treat 2016;2:259-67.

22. Solomon W, Leung Wenjuan G, Tae Hwan James C.K. Lai Effect of Chitosan and Nanoparticles on Cancer Cells Treated with Therapeutic Drugs: Comparison of Cell Survival, advance in nano biomechanics robot and energy research, the world congress, 2013.

23. Wimardhani YS, Suniarti DF, Freisleben HJ, Wanandi SI, Siregar NC, Ikeda M-A. Chitosan exerts anticancer activity through induction of apoptosis and cell cycle arrest in oral cancer cells. J Oral Sci 2014;56(2):119-26.

24. Rauw F, Gardin Y, Palya V, Anbari S, Gonze M, Lemaire $\mathrm{S}$, et al. The positive adjuvant effect of chitosan on antigen-specific cell-mediated immunity after chickens vaccination with live Newcastle disease vaccine. Vet Immunol Immunopathol 2010;134(3-4):249-58.

25. Bowman K, Leong KW. Chitosan nanoparticles for oral drug and gene delivery. Int $\mathrm{J}$ Nanomedicine 2006;1(2):117-28.

Gregory AE, Titball R, Williamson D. Vaccine delivery using nanoparticles. Front Cell Infect Microbiol 2013;3:13. 